\title{
Psychiatric comorbidity in diabetes type 1: a cross-sectional observational study
}

Ana Claudia C. de Ornelas Maia ${ }^{1}$, Arthur de Azevedo Braga ${ }^{1}$, Flávia Paes ${ }^{1,2}$, Sergio Machado ${ }^{1,2,3,4,5}$, Antonio Egidio Nardi $^{1,2}$, Adriana Cardoso Silva ${ }^{1,2}$

${ }^{1}$ Laboratory of Panic and Respiration - Institute of Psychiatry of Federal University of Rio de Janeiro, Rio de Janeiro, RJ, Brazil

${ }^{2}$ National Institute of Translational Medicine (INCT-TM), Rio de Janeiro, RJ, Brazil

Institute of Philosophy, Federal University of Uberlândia, Uberlândia, MG, Brazil

${ }^{4}$ Chiropractic program of the Faculty of Medical Sciences, Central University (UCEN), Santiago, Chile

${ }^{5}$ Physical Activity Sciences Postgraduate Program - Salgado de Oliveira University, Niterói, RJ, Brazil

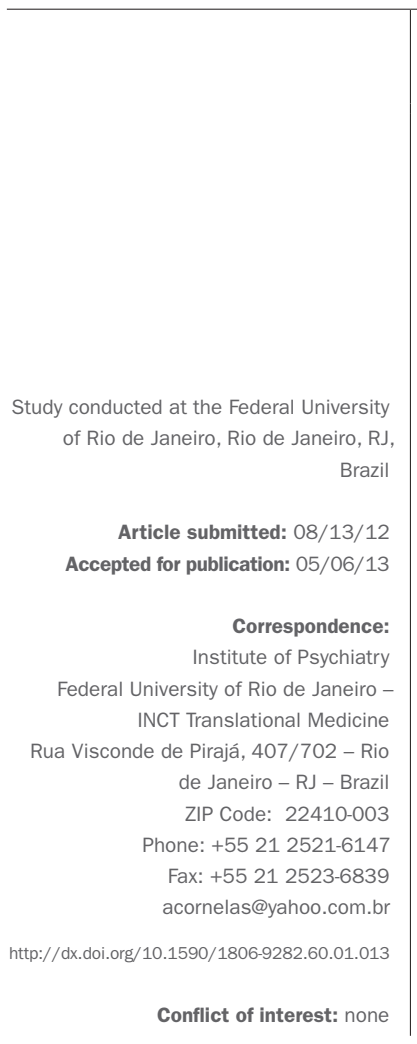

\section{SUMmarY}

Objective: This study aims to investigate the prevalence of psychiatric disorders, i.e., the presence of signs and symptoms of anxiety and depression in type 1 diabetic patients, as well as to investigate the prevalence of psychiatric disorders in insulin dependent patients.

Methods: A cross-sectional observational study of 110 diabetic outpatients (mean $=58.3, \mathrm{SD}=14.5 ; 50$ male and 60 female) was conducted in a public health clinic with patients diagnosed with diabetes mellitus who were under the medical supervision of an endocrinologist. The patients were evaluated through the Mini International Neuropsychiatric Interview and the Hospital Anxiety and Depression Scale (HADS). Results: With respect to anxiety symptoms, we found a prevalence of $60 \%(\mathrm{n}=$ 66) among patients, while in depression symptoms we found a prevalence of $53.6 \%(\mathrm{n}=59)$ concerning the 110 patients evaluated. More specifically, we found $28.2 \%(n=31)$ of patients without depression or anxiety, $13.6 \%(n=15)$ of patients with depression, $16.4 \%(n=18)$ of patients with anxiety and $41.8 \%(n=46)$ of patients with depression combined with anxiety. The most remarkable data were generalized anxiety disorder (22.7\%), dysthymia (18.2\%), panic disorder (8.2\%) and social phobia (5.5\%).

Conclusion: The need for accurate assessments about the presence of symptoms related to psychopathology in patients with type 1 diabetes is evident.

Key words: Anxiety. Depression. Prevalence and Diabetes.

\section{INTRODUCTION}

Studies indicate that groups of chronic diseases, such as type 1 diabetes, can present severe psychiatric disorders. Faced with direct relationship of type 1 diabetes with mental health, studies demonstrate that the prevalence of psychiatric disorders in diabetic patients may reach $84 \%$ for mood disorders and $80 \%$ for anxiety disorders ${ }^{1}$. A previous study ${ }^{2}$ evaluated the presence of psychiatric comorbidities both in patients with diabetes types 1 and 2 . The first group showed higher values for the presence of general anxiety disorder $(24 \%)$, dysthymia $(20 \%)$, social phobia (6\%), depression (9\% for current and 5\% for lifelong), panic disorder (5\%) and suicide risk (3\%), all values were higher than those found in the general population or in patients with type 2 diabetes. The instrument used in this study was the Mini International Neuropsychiatric interview, which is aimed to detecting psychiatric disorders ${ }^{2}$.

Patients with a high prevalence of psychiatric disorders have further compromising their mental health when assessed in terms of signs and symptoms. The presence of psychiatric signs and symptoms, and more specifically depression and anxiety, can increase morbidity, and lead to worse clinical prognosis.

\section{Objective}

This study aims to confirm the prevalence of psychiatric disorder and assess the prevalence of depression and anxiety signs and symptoms in patients with type 1 diabetes. 


\section{Methods}

A cross-sectional observational study was conducted, consisting of 110 diabetic outpatients (mean $=58.3, \mathrm{SD}=14.5$; 50 male and 60 female) from a public health clinic with diagnoses of type 1 diabetes mellitus who were under the medical supervision of an endocrinologist. To confirm the findings of a previous study ${ }^{2}$ regarding the prevalence of psychiatric disorders, patients were assessed with the Mini International Neuropsychiatric Interview (MINI). To evaluate the prevalence of depression and anxiety signs and symptoms the Hospital Anxiety and Depression Scale (HADS) was used. Patients signed a consent form and were aware of the experimental protocol (approved by the Ethics Committee at the Federal University of Rio de Janeiro) before participation commenced.

\section{RESULTS}

Descriptive data from participants diagnosed as having type 1 diabetes, including sex, age, education, occupation, religion, children, and the use of psychotropic drugs, are shown in Table 1.

TABLE 1 Characteristics of type 1 diabetic patients

\begin{tabular}{|c|c|}
\hline & Patients with type 1 diabetes \\
\hline \multicolumn{2}{|l|}{ Sex } \\
\hline Female & $60(54.5 \%)$ \\
\hline Male & $50(45.5 \%)$ \\
\hline \multirow[t]{2}{*}{ Age } & $58.3( \pm 14.5 \%)$ \\
\hline & Minimum $=18 ;$ Maximum $=82$ \\
\hline \multicolumn{2}{|l|}{ Marital status } \\
\hline Single & $17(15.5 \%)$ \\
\hline Married & $60(54.5 \%)$ \\
\hline Divorced & $11(10 \%)$ \\
\hline Widow/Widower & $22(20 \%)$ \\
\hline \multicolumn{2}{|l|}{ Occupation } \\
\hline Student or housewife & $22(20 \%)$ \\
\hline Unemployed & $3(2.7 \%)$ \\
\hline Working & $35(31.8 \%)$ \\
\hline On leave & $5(4.5 \%)$ \\
\hline Retired & $45(40.9 \%)$ \\
\hline \multicolumn{2}{|l|}{ Religion } \\
\hline Atheist & $4(3.6 \%)$ \\
\hline Catholic & $74(67.3 \%)$ \\
\hline Evangelic & $24(21.8 \%)$ \\
\hline Other & $8(7.3 \%)$ \\
\hline \multicolumn{2}{|l|}{ Education } \\
\hline Elementary school & $74(67.3 \%)$ \\
\hline High school & $25(22.7 \%)$ \\
\hline College or Higher education & $11(10 \%)$ \\
\hline \multicolumn{2}{|l|}{ Children } \\
\hline Yes & $95(86.4 \%)$ \\
\hline No & $15(13.6 \%)$ \\
\hline \multicolumn{2}{|l|}{ Use of Psychotropic Drugs } \\
\hline Yes & $20(18.2 \%)$ \\
\hline No & $90(81.8 \%)$ \\
\hline
\end{tabular}

With regard to prevalence of psychiatric disorders, table 2 shows the total number of patients with diabetes who presented each of the psychiatric disorders identified in the sample, with percentages in decreasing order.

TABLE 2 Prevalence of psychiatric disorders in type 1 diabetic patients

\begin{tabular}{l|l|l} 
Disorder & N & (\%) \\
\hline Generalized anxiety disorder & 25 & 22.7 \\
\hline Dysthymia & 20 & 18.2 \\
\hline Current depression & 9 & 8.2 \\
\hline Panic disorder & 6 & 5.5 \\
\hline Social phobia & 6 & 5.5 \\
\hline Life-long depression & 5 & 4.5 \\
\hline Hypomanic episode & 3 & 2.7 \\
\hline Risk of suicide & 3 & 2.7 \\
\hline Agoraphobia & 1 & 0.9 \\
\hline Dependence/Abuse of substance & 1 & 0.9 \\
\hline Manic episode & 1 & 0.9
\end{tabular}

Considering that some patients may present signs and symptoms without necessarily meet the criteria for a diagnosis of a psychiatric disorder, we also considered important to assess the presence of anxiety and depression sings and symptoms, which may or may not be superimposed, at this level. According to HADS, $60 \%(\mathrm{n}=66)$ and $53.6 \%$ $(n=59)$ of the patients have signs and symptoms of anxiety and depression, respectively. Evaluating the clinical picture, considering possible superposition, we found only $28.2 \%$ of patients $(n=31)$ without depression or anxiety, $13.6 \%$ of patients $(n=15)$ with depression, $16.4 \%$ of patients $(n=18)$ with anxiety and the larger group, $41.8 \%$ of patients $(n=46)$, with depression combined with anxiety setting the most serious situation.

\section{Discussion}

We observed that the prevalence of psychiatric comorbidity (mainly anxiety and depression) in type 1 diabetes, as a disorder as well as a set of signs and symptoms, is significantly higher in diabetic patients than those found in the general population.

Sample characteristics found in this study for variables such as sex, age, marital status, occupation, education and even religion were similar to those found in a previous study ${ }^{2}$ as well as prevalence rates for psychiatric disorders. In addition, this study presents data on the prevalence of signs and symptoms of anxiety $(60 \%)$ and depression (53.6\%), also considered elevated and definite- 
ly higher than those found in the non-clinical population. When mental health was evaluated only by disorder, the higher prevalence found was for GAD $(22.7 \%)$ and Dysthymia (18.2\%) while all other disorders had prevalence below $10 \%$. Thus, understanding the presence of psychiatric impairment at the level of signs and symptoms enables us to better understand the actual mental health status of the patient.

Considering that anxiety and depression are factors that affect the clinical picture of diabetes and also compromise treatment adherence, fundamental for these patients, the severity of mental health impairment in these patients is clear. This is especially true when we realize that only $28.2 \%$ of them show no anxiety or depression, according to the HADS, while $41.8 \%$ of the subjects present both anxiety and depression combined.

The prevalence of depression in patients with diabetes is about 2 to 4 times greater than that seen in the general population, which may affect up to $30 \%$ of diabetics, and a meta-analysis confirmed the double risk of depression in diabetics, as well as demonstrated that diabetic women have a higher risk of depression (28\%) than diabetic men $(18 \%)^{3}$. Another relevant factor is anxiety in type 1 diabetic patients, which can be related to glycemic control. The contingency to be in balance with health can generate greater concern compared to people who don't have the disease ${ }^{3,4}$.

With respect to depression, some studies demonstrated that type 1 diabetic patients have a probability 3 or 4 times higher to develop suicidal ideation, compared to non-diabetic patients $(13.3 \%$ vs. $3.5 \%$, respectively; $\mathrm{p}=$ $0.001)^{5}$. Moreover, the findings in research ${ }^{6}$ showed that there is a high prevalence of psychiatry disorders in type 1 diabetic patients (e.g., $1 \%$ of agoraphobia, $3 \%$ of hypomanic episode, and $1 \%$ of manic episode) associated with anxiety-phobia and depression disorders, which supports our results. The study ${ }^{7}$ revealed that among 224 type 1 diabetic patients with hypoglycemic episodes, for instance, $74 \%$ had agoraphobia. Other studies indicated that the prevalence of mood disorders is significantly higher in type 1 diabetic patients ${ }^{8}$ (i.e., $15 \%$ of dysthymia, $11 \%$ of current depression and $5 \%$ of panic disorder), reaching up to $67 \%$. A possible explanation for such high prevalence, more specifically in the case of dysthymia, was probably due to the inadequacy of psychological and psychiatric treatment performed in the study. Dysthymia, which is usually accompanied by significant functional impairment, is related to estimative of individuals who are managing it at any given time, reaching around $4 \%$ to $6 \%$ of the general population ${ }^{10,11}$. In line with this, the study ${ }^{12}$ demonstrated that dysthymic patients are at increased risk for poor general health, and when compared with the general population, they frequently use medical services and are among patients with several medical disorders.

Another important evidence comes from a meta-analysis $^{13}$ that the odds of depression in type 1 diabetic patients were twice that of the non-diabetic patients (OR, 2.0; 95\% CI, 1.8-2.2). With regard to anxiety disorders, panic disorder, a severe and devastating condition marked by recurrent and unexpected attacks of sudden onset and short duration related to physiological anxiety sensations (such as subsequent hyperventilation, palpitations, chest pain, nausea, numbness) $)^{14,15}$ seems similar to the symptoms of hypoglycemia, frequently observed in type 1 diabetes.

In addition to the signs and symptoms of anxiety and depression in type 1 diabetes, both the physiological changes in the chronic course of the disease: weight gain, pain, hypertension, heart disease, loss of motor skills, or blindness directly affect the emotional state ${ }^{2}$.

\section{Conclusion}

Therefore, we observed high prevalence of psychiatric disorders in type 1 diabetes. Moreover, we observed that $60 \%$ and $53.6 \%$ of the patients have signs and symptoms of anxiety and depression, respectively. More specifically, taking into account the clinical picture and possible superposition, we found only $28.2 \%$ of patients without depression or anxiety, $13.6 \%$ of patients with depression, $16.4 \%$ of patients with anxiety, and the larger group, $41.8 \%$ of patients, with depression combined with anxiety setting the most serious situation. Thus, we propose that physiological symptoms of hypoglycemia and hyperglycemia, such as, weight gain, pain, hypertension, heart disease, loss of motor skills, or blindness, can be associated with anxiety disorders, due to the generation of sensations similar to anxiety disorders, which can also change the mood of individuals.

The need for accurate assessments for the presence of symptoms related to psychopathology in patients with diabetes is evident, as well as the development of therapeutic protocols that consider the physical, psychological and social conditions of this population.

\section{Resumo}

Comorbidade psiquiátrica no diabetes tipo 1: um estudo transversal observacional.

Objetivos: Elementos relacionados à saúde mental do paciente diabético tipo 1 são encontrados em várias pesquisas. O objetivo desse estudo é avaliar sinais e sintomas depressivos nesse grupo de pacientes, como também in- 
vestigar as principais prevalências psiquiátricas que os acometem.

Métodos: Pesquisa realizada em 110 pacientes diabéticos atendidos em ambulatórios (média $=58.3, \mathrm{D}=14.5$; 50 masculinos e 60 femininos) conduzida em Postos de Saúde Pública nos momentos de consulta médica com endocrinologista. A avaliação transcorreu com as escalas Mini International Neuropsychiatric Interview and Hospital Anxiety and Depression Scale (HADS).

Resultados: Os sintomas de ansiedade tiveram prevalência de $60 \%(n=66)$, enquanto para depressão encontramos resultados de $53.6 \%(n=59)$, considerando que 110 pacientes foram avaliados. Mais especificamente, nós encontramos 28,2 (n. 31) pacientes sem depressão ou ansiedade, 13,6 (n. 15) pacientes com depressão, 16,4 pacientes (n. 18) com ansiedade e 41,8 (n. 46) pacientes com depressão combinada com ansiedade. Outros transtornos comórbidos tiveram prevalência de ansiedade generalizada $(22,7 \%)$, distimia $(18,2 \%)$, pânico $(8,2 \%)$ e fobia social $(5,5 \%)$.

Conclusão: Sintomas ansiosos e depressivos são comuns em pacientes diabéticos do tipo 1 , porém há prevalência de psicopatologias diversas nesse grupo de pacientes, levando em conta novas necessidades de pesquisas futuras para validar protocolos de tratamentos mais adequados para diabéticos do tipo 1 .

Unitermos: Ansiedade, depressão, diabetes, prevalência.

\section{References}

1. Chaudhry R, Mishra P, Mishra J, Parminder S, Mishra BP. Psychiatric morbidity among diabetic patients: a hospital-based study. Ind Psychiatry J. 2011;19(1):47-9.

2. De Ornelas Maia AC, Braga Ade A, Brouwers A, Nardi AE, De Oliveira e Silva AC. Prevalence of psychiatric disorders in patients with diabetes types 1 and 2. Compr Psychiatry. 2012;53(8):1169-73.

3. Musselman DL, Betan E, Larsen HE, Phillips LS. Relationship of depression to diabetes types 1 and 2: Epidemiology, biology, and treatment. Biol Psychiatry. 2003;54(4):317-29.

4. Brieger P, Marneros A. Dysthymia and cyclothymia-serious consequences of rarely diagnosed disorders. Versicherungsmedizin. 1998;50(6):215-8.

5. Engum A. The role of depression and anxiety in onset of diabetes in a large population-based study. J Psychosom Res. 2007;62(1):31-8.

6. Berlin I, Bisserbe JC, Eiber R, Balssa N, Sachon C, Bosquet F, et al. Phobic symptoms, particularly the fear of blood and injury, are associated with poor glycemic control in type I diabetic adults. Diabetes Care. 1997;20(2):176-8.

7. Costea M, Ionescu-Tîrgoviote C, Chela D. Mincu I. Fear of hypoglycemia in type 1 (insulin-dependent) diabetic patients. Rom J Intern Med. 1993;31(4):291-5

8. Magee WJ, Eaton WW, Wittchen HU. Agoraphobia, simple phobia and social phobia in the national comorbity survey. Arch Gen Psychiatry. 1996;53(2):15968.

9. Eren I, Erdi O, Ozcankaya R. Relationship between blood glucose control and psychiatric disorders in type II diabetic patients. Turk Psikiyatri Derg. 2003;14(3):184-91

10. Noyes R, Moroz F, Davidson JRT, Liebowitz MR, Davidson A, Siegel J, et al. Moclobemide in social phobia: a controlled dose-response trial. J Clin Pharmacol. 1997;17(4):247-54.

11. Clavijo M, Carvalho JJ, Rios M, De Oliveira IR. Psychiatric disorders in patients with diabetes type 2 at medical care and training district of Rio Branco-Acre, Brazil. Arq Neuropsiquiatr. 2006;64(3B):807-13.

12. Howland RH. General health, health care utilization, and medical comorbidity in dysthymia. Int J Psychiatry Med. 1993;23(3):211-38.

13. Anderson RJ, Freedland KE, Clouse RE, Lustman PJ. The prevalence of comorbid depression in adults with diabetes: a meta-analysis. Diabetes Care. 2001;24(6):1069-78.

14. Gannon MA, Qaseem A, Snow V, Turner B. Raising achievement: educating physicians to address effects of at-risk drinking on common diseases. Qual Prim Care. 2011;19(1):43-7.

15. Gannon M, Qaseem A, Snow V. Community-based primary care: improving and assessing diabetes management. Am J Med Qual. 2010;25(1):6-12. 